\title{
Study of arterial pattern of normal human placenta in reference to its shape, weight and Hyrtl's Anastomosis
}

\author{
Soni $\mathrm{S}^{1}$, Bhardwaj $\mathrm{K}^{2}$, Garg $\mathrm{S}^{3}$, Mishra S.K. ${ }^{4}$ \\ ${ }^{1}$ Dr. Sachin Soni, Assistant Professor, Department of Anatomy, Veer Chandra Singh Garhwali Govt. Institute of Medical \\ Science \& Research, Srinagar, Pauri- Garhwal, Uttarakhand; ${ }^{2}$ Dr. Kamal Bhardwaj, Lecturer, Department of Anatomy, \\ S.N. medical College, Agra; ${ }^{3}$ Dr. Shikky Garg, Associate Professor, Department of Anatomy, S.N. Medical College, \\ Agra, ${ }^{4}$ Dr. Sandeep Kumar Mishra, Professor, Department of Anatomy, Veer Chandra Singh Garhwali Govt. Institute of \\ Medical Science \& Research, Srinagar, Pauri- Garhwal, Uttarakhand, India
}

Address for Correspondence: Dr. Sachin Soni, Assistant Professor, Department of Anatomy, Veer Chandra Singh Garhwali Govt. Institute of Medical Science \& Research, Srinagar, Pauri- Garhwal, Uttarakhand, E Mail IDsachin.vcsg@gmail.com

\begin{abstract}
Background: Study of placenta in reference to its blood supply is very important for the reason that it is highly vascular organ which directly influences the growth and development of foetus. The shape of placenta, its weight together with Hyrtl's anastomosis also directly or indirectly affects the health and wellbeing of the foetus. Material \& Method: 104 placentae were collected from Labour room, Gynaecology \& Obstetrics Department and Lady Loyal Hospital. After cleaning and morphometry, Barium Sulphate was injected in the vascular tree of the placentae. Finally after radiography, observations were recorded. Results: dispersed pattern of Arterial pattern was found in 72.88 percent placentae and in remaining 27.11 percent, Magestrial pattern was present. Average weight of placentae in the study was 468.4 gm. Hyrtl's anastomosis was present in 100 out of 104 placentae. Conclusion: study of vasculature of Placentae revealed that percentage of dispersed and magestrial pattern of placentae in north Indian population is not same as that reported in other studies of different regions.
\end{abstract}

Keywords: Placenta, Arterial pattern, Hyrtl's anastomosis, Dispersed, Magisterial

\section{Introduction}

In intra uterine life, foetus depends upon the placenta as its lungs, liver, \& kidney [1]. The well being of the foetus is affected by many factors but a healthy placenta is the single most important factor in producing a healthy baby [2].

The placenta is a unique characteristic of higher mammals which is attached to the uterus and is connected to the foetus through the umbilical cord. Researchers have, emphasized the benefits which are associated with the anatomical examination of the placenta, an organ that is often disposed soon after parturition, without adequate examination. The examination of the placenta in utero as well as

Manuscript received: $14^{\text {th }}$ April 2017

Reviewed: $20^{\text {th }}$ April 2017

Author Corrected: $30^{\text {th }}$ April 2017

Accepted for Publication: $10^{\text {th }}$ May 2017 postpartum, gives valuable information about the state of the fetal wellbeing [3]. Placenta provides most accurate record of infant's prenatal experience [4].

After delivery the detailed \& fine examination of placenta provides much information about prenatal health of the baby and the mother [5]. Hence this study was done to correlate the shape of the placenta with the arterial patterns of placenta. At term, the placenta is discoid with a diameter of 15 to $25 \mathrm{~cm}$ and is approximately $3 \mathrm{~cm}$ thick and weighs about 500 to 600 g [6]. Placental thickness increases with age of the foetus [7].

The chorionic plate (or "fetal surface") of the human placenta is typically drawn as round, with the umbilical cord inserted roughly at the center [8]. In clinical 
practice, the shape of the chorionic disk is rarely truly circular; its shape commonly varies, from round to oval, or regularly irregular [9]. Kaplan, (1995) reported that the shape of placentae vary from discoid, circular and discoid with accessory lobes structure which is the extension into the mother from the foetus [10].

It is reported previously that pregnancy outcome was associated with placental weight. Altered growth of placenta was a predictor of maternal mediated diseases (cardiovascular diseases, Hypertension and diabetes mellitus) [11]. Low weight of placenta was associated with medical complications in the mother. On the other hand high placental weight was associated with poor perinatal outcome, low Apgar score, respiratory distress syndrome and perinatal death [12]. Methodology of preparation, weighing of placenta together with cord clamp time may lead to variations in the mean weight of placenta. Arrangement of arteries in human placenta has been compared to spokes of wheel [13] and star like radiation and vessels described into primary, secondary and tertiary groups [14] all arteries within the placenta are considered as end arteries [15]. The pattern of

\section{Material and Method}

Study Design: It was a discreptive study carried out to investigate the arterial pattern of normal human placentae. The Hyrtl's anastomosis, shape and weight of placentae were further studied in detail in reference to the arterial pattern. Placentae for present study were collected from labour room and operation theatre, S.N. Medical College, Agra and Lady Loyal Hospital Agra and Normal term placentae were taken for study and any abnormal placenta was excluded.

Study/Sample size: 104 normal human placentae were taken from labour room and operation theatre, S.N. Medical College, Agra and Lady Loyal Hospital Agra for the present study.

Inclusion Criteria: Normal, term human placentae were taken for study.

Exclusion Criteria: The exclusion criteria ruled out morbidity adherent placenta, abruption placenta, retained placenta, placenta in precplempsia and diabetic mother. Placentas of twin pregnancy and of preterm babies were also excluded.

\section{Shape and weight of placenta}

Shapes of the placentae were divided in the following categories and were recorded [9] :-

1. Circular

2. Oval

3. Irregular (Fig.1).

Weight was taken after trimming extra placental membranes from the placenta.they were weighed in table top beam weighing scale. Finally weight of each placenta was recorded.

Estimation of Arterial Pattern- The arterial pattern of placentae was confirmed by the following methods:-

X-Ray Radiography- Placentae were squeezed and cleaned properly. 30 gm BaSO4 was dissolved in100 ml of water. Umbilical arteries were identified in the umbilical cord. 15 NO. needle was inserted in one umbilical artery, tied with 
thread and the artery was cleaned by injecting plane water. Again water was squeezed out and 15-20ml of BaSO4 solution was injected in the arterial tree with a constant uniform pressure. The artery was firmly tightened and this same procedure was repeated with the other artery also. Finally the placenta was tagged.

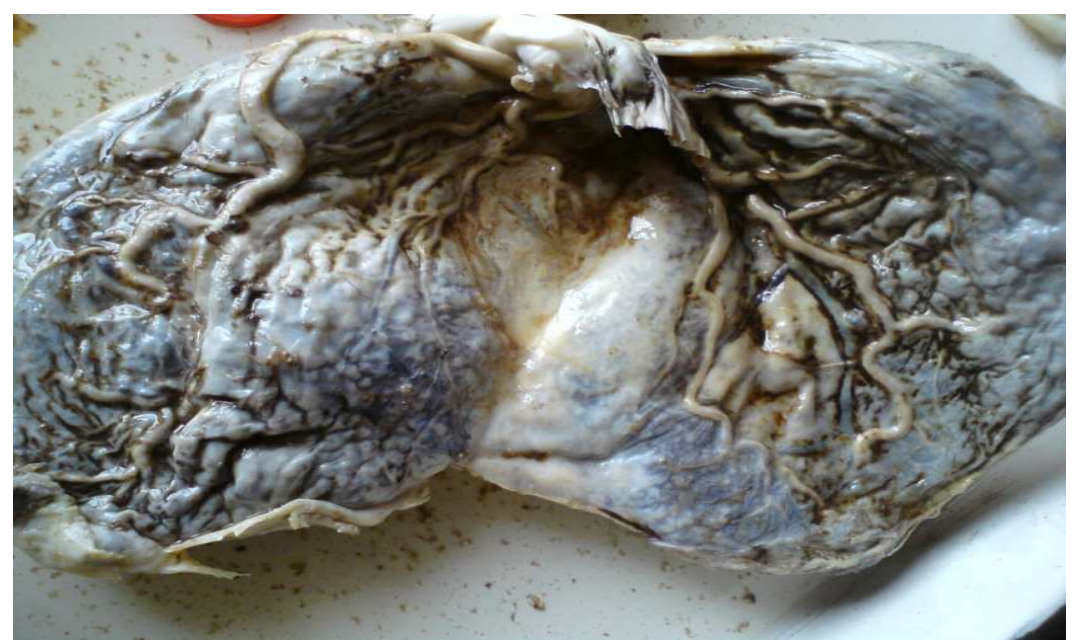

Fig-1: irregular shaped placentae after filling Barium Sulphate

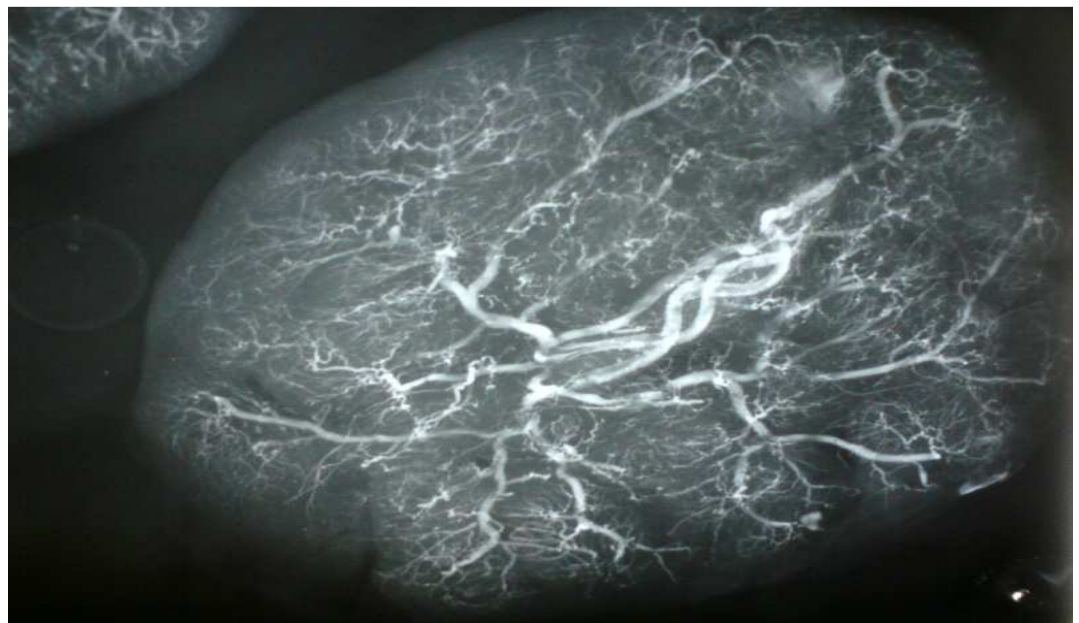

Fig-2: Oval shaped placentae with dispersed irterial pattern

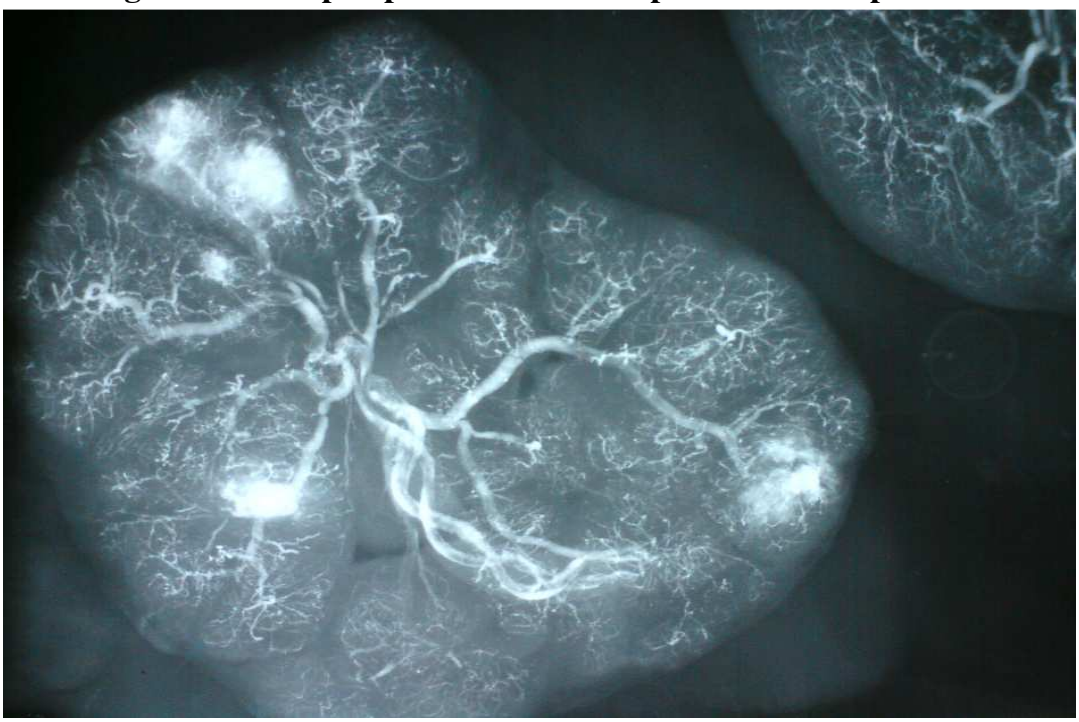

Fig-3: placentae with magestrial type of arterial pattern 
On the same day, x-ray films were taken of the filled placenta. The arterial patterns were observed and recorded. Placentae with ratio of diameter of chorionic blood vessels at periphery and at center were evaluated. If it stood less than or equal to half, than it was placed in dispersed group (Fig.2) but if it was more than half than it was grouped under magestrial variety (fig 3). Microsoft Excel sheets were used to tabulate and record the data and master chart was prepared. Finally analysis of the data was done

\section{Observation \& Results}

We observed that out of 104 placentae selected for study, 75 were having dispersed type of arterial pattern and 29 were of magistral type of arterial pattern.

72.88 Percent of placentae belonged to dispersed type while remaining 27.11 percent belonged to magistral type.

The distribution of placental shape according to arterial pattern is shown in the table NO. 1. Table shows that majority of round placentae were of dispersed arterial pattern while irregular placentae were of magistral pattern. Out of 44 round shaped placentae, only 4 have had magestrial pattern and rest 40 were of dispersed type. Oval shaped placentae also followed the trend and 8 out of 39 placentae reported magestrial pattern while 31 reported dispersed pattern. In the group with irregular shaped placentae, 17 out of 21 presented with magestrial pattern while 4 with dispersed type.

Table No.-1: Showing distribution of placental shape according to arterial pattern

\begin{tabular}{|l|l|l|l|l|l|}
\hline \multirow{2}{*}{$\begin{array}{l}\text { Shape of } \\
\text { placenta }\end{array}$} & Dispersed pattern & Magistral pattern & \multirow{2}{*}{ Total } \\
\cline { 2 - 6 } & Number & Percentage & Number & Percentage & \\
\hline Round & 40 & 38.46 & 4 & 3.84 & 44 \\
\hline Oval & 31 & 29.80 & 8 & 7.692 & 39 \\
\hline Irregular & 4 & 3.84 & 17 & 16.35 & 21 \\
\hline Total & $\mathbf{7 5}$ & $\mathbf{7 2 . 1 1}$ & $\mathbf{2 9}$ & $\mathbf{2 7 . 8 8}$ & $\mathbf{1 0 4}$ \\
\hline
\end{tabular}

Weight of placentae in our study oscillated in a wide range from 342 gram to 568 gram. In our study mean weight of all the placentae was reported 468.4 grams. Mean weight of placentae with dispersed type of arterial pattern was 464 grams. While it was 480 grams in placentae with magestrial type of arterial pattern.

Out of 104 placentae, hyrtl's anastomosis was present in 100 placentae. It was absent in 3 and one placenta was devoid of second umbilical artery. Hyrtl's anastomosis was present in all the placentae with dispersed type of arterial pattern. Out of 29 placentae with magestrial pattern, 25 presented with Hyrtl's anastomosis. Only single Hyrtl's anastomosis was seen in the cases and none of them carried anastomosis in more than one site.

\section{Discussion}

Although the role of placenta is very important in uman development, still study of fetus is ahead of studiy of placenta [1]. Studies of the vascular anatomic pattern of the placenta have been made almost excliusively with the use of injection corrosion technique [14, 20, 21]. Crawford (1962) used a similar method based on placental dissection made after trypsin digestion [22].

For the above reason, we considered worthwhile to undertake the present study. We preferred the methods of x-ray radiography because a clear concept of vessels in the placenta cannot be obtained by an ordinary dissection.
Vasculature of foetal placenta is recognizable at twelth week of intrauterine life [14]. In the present study we found that arterial pattern of human placenta can be of two types, dispersed type or magistral type. This is in accordance with studies conducted by Schordania [16]. The vascular pattern of the placenta is not a haphazard phenomenon, but is genetically determined by vascular characteristics of the mother.

Our study revealed that 72.88 Percent of placentae belonged to dispersed type while 27.11 percent belonged to magistral type of arterial pattern which is different from than that of Schordania as according to him both varieties are about equal in incidence [16]. It 
also differs from the result of Cunnigham et al who described dispersed pattern as 63 percent and magestrial variety as 37 percent [23].

We also noticed that all the main arterial branches of the placenta lied in a horizontal plane, a fact reported by Spanner [19] and Bacsich and Smout [14]. This is an important finding as in almost all other body organs the arterial tree acquires three dimensional lattice. Fraser described the arteries of the human placenta as being similar in their arrangement to the spokes of a wheel [13].

93 percent of placentae belonged to round shape and 7 percent were oval shaped in a study conducted in Tamil Nadu by G. Ragunath and Vijayalakshmi [24]. We classified placentae according to M. Yampolsky and found that 42.30 percent placentae were of round shape, 37.5 percent placentae were of oval shape and the rest 20.19 percent were of irregular shape [9].

Relationship between placental weight and fetal growth was established in studies [25]. Mean placental weight in Asia was recorded $588 \mathrm{gm}, 480 \mathrm{gm}$ in Ukraine, 643 gm in Western Europe and 630 gm in Nigeria.[ 25-28]. In our study we found mean placental weight as 468.4 gm. It varied from 342 gram to 568 gram. It is lowest in comparison to above studies. It was recorded as $425 \mathrm{gm}$ in another study conducted in India [29]. Methods of preparation and weighing of placenta along with cord clamping time may lead to this large variation in the mean weight of the placentae [30]. It may get affected by ethinicity and unknown factors [31].

Also it was recorded that weight of placenta in case of babies delivered by caesarean section was higher than that of in case of babies delivered vaginally [32], as clamping is relatively late in vaginal delivery and early clamping is usually a rule in caesarean section cases [33]. The intervillous space in placenta is likely to contain more maternal blood in caesarean section due to absence of uterine contractions in comparison to placenta with vaginal delivery as maternal blood is pushed out of inervillous space due to contractions of uterus [33]. Placentae from multiparous women are heavier than from primiparous women as recorded in few studies [32, 34].

Normally one single anastomosis is present in between two umbilical arteries but 2 anastomoses were recorded in few placentae as reported by Patel et. al [5]. U Ulberg found anastomosis between the umbilical arteries in 60 out of 64 cases [17]. All have single anastomosis. They further classified it in to complete vessel, fenestration or fusion of two vessels. In our study we recorded 100 out of 104 placentae with hyrt's anastomosis which was close to placental end of umbilical cord. We also verified that all anastomoses were single. We further noticed the presence or absence of anastomosis in reference to arterial pattern of placentae. We found that all placentae with dispersed type of arterial pattern were having the anastomosis whereas 25 out of 29 placentae with magisterial type of arterial pattern carried Hyrtl's anastomosis. One case in our study featured only single umbilical artery.

The importance of placental studies has reached a new dimension with its use for medico legal purposes. Placenta is used as a witness for medico legal purposes as in case of cerebral palsy. Gross examination of small sized placenta will tell that it was insufficient blood supply in utero and not medical negligence due to which cerebral palsy happened. In case of death of neonate due to severe anemia, placental small weight, lesser volume, which are compensatory mechanism to maternal hypoxia will help medical practitioners to defend themselves. [13].

\section{Conclusion}

In our study we found that dispersed type of arterial pattern of normal human placentae in north Indian population was almost three times more common than that of magestrial type. The mean placental weight was found to be $468.4 \mathrm{gm}$. We also noticed that majority of irregular shaped placentae belonged to magestrial type of arterial pattern. It requires further deep study in relation to foetal outcome. The increasing role of placentae as medico legal evidence requires further look in Anatomical and Physiological aspect of placentae.

\section{Acknowledge}

\section{Funding: Nil, Conflict of interest: None Permission of IRB: Yes}

\section{References}

1. Verma, R.; Prasad, R.; Mishra, S. \& Kaul, J. M. Vascular pattern of chorionic blood vessels of placenta 
and its correlation with the birth weight of neonate. Int. J. Morphol. 2012;30(3):952-955.

2. van den Broek N, Ntonya C, Kayira E, White S, Neilson JP. Preterm birth in rural Malawi: high incidence in ultrasound-dated population. Hum Reprod. 2005 Nov;20(11):3235-7. Epub 2005 Jul 21.

3. Kouvalainen K, Pynnönen AL, Mäkäräinen M, Peltonen T. [Weights of placenta, fetal membranes and umbilical cord]. Duodecim. 1971;87(17):1210-4.

4. Salmani D, Purushothaman S, Somashekara SC, Gnanagurudasan E, Sumangaladevi K, Harikishan R, Venkateshwarareddy M. Study of structural changes in placenta in pregnancy-induced hypertension. J Nat Sci Biol Med. 2014 Jul;5(2):352-5. doi: 10.4103/09769668.136182.

5. Patel J, Patel B, Dave R, Ram S, Bhojek N, desai J; A study of placental vascular pattern by corrosive cast in Gujarat region; NJRM 2014;5(1) : 64-71.

6. Sadler TW. Langman's medical embryology. 9th Edition.Baltimore,MD:Lippencott Williams and Wilkins2004; 148-178.

7. Tongsong T, Boonyanurak P. Placental thickness in the first half of pregnancy. J Clin Ultrasound. 2004 Jun;32(5):231-4.

8. Benirschke K, K.P., Architecture of Normal Villous Trees, Chapter 7, in Pathology of the Human Placenta., Springer Verlag: New York, New York. 2002 p. 116154.

9. M. Yampolsky, Placental characteristics and birthweight. Paediatr Perinat Epidemiol. 1998 May; 22(3):229-39.

10. Kaplan, C Color Atlas of Gross Placental Pathology, New York, Igaku-Shoin, 1994:20-42.

11. Barker DJ, Bull AR, Osmond C, Simmonds SJ. Fetal and placental size and risk of hypertension in adult life. BMJ 1990 Aug;301:259-62.

12. Naeye RL. Do placental weights have clinical significance? Hum Pathol 1987 April;18:387-91.
13. Fraser, J. Amer. J. Obstet. Gynaec. 1923; 4:645655.

14. Bacsich P.and Smout C.F.V. some observations of the fetal vessels. J. Anatomy 1938; 72:358.

15. Shordania, J. Arch. Gynak. (1929) 135: 568. doi:10.1007/BF01702300.

16. Ullberg U, Sandstedt B, Lingman G. Hyrtl's anastomosis, the only connection between the two umbilical arteries. A study in full term placentas from AGA infants with normal umbilical artery blood flow. Acta Obstet Gynecol Scand. 2001 Jan;80(1):1-6.

17. PRIMAN J. A note on the anastomosis of the umbilical arteries. Anat Rec. 1959 May;134:1-5.

18. Young A. The primate umbilical cord with special reference to the transverse communicating artery. J Hum Evol 1972; 1: 345-359.

19. Spanner, R. Z. Anat. Entwickl. Gesch. (1935) 105: 163. doi:10.1007/BF02118325.

20. ROMNEY SL, REID DE. Observations on the fetal aspects of placental circulation. Am J Obstet Gynecol. 1951 Jan;61(1):83-98.

21. Crawford JM (1962). Vascular anatomy of the human placenta. Am J of Obstet. Gynecol. 84: 15431567.

22. G. Ragunath and Vijayalakshmi A study of morphology of human placenta,J. of clinical and diagnostic research 2011; vol.5,282-286.

23. Bleker OP, Wolf H, Oosting J.. The placental cause of fetal growth retardation in twin gestations. Acta Genet Med Gemellol (Roma). 1995; 44(2):103-6.

24. Perry IJ, Beevers DG, Whincup PH, Bareford D. Predictors of ratio of placental weight to fetal weight in multiethnic community. BMJ. 1995 Feb 18;310(6977):436-9.

25. Adinma JI, Agbai AO. Foetal birth weight in Africa. J Obstet Gynaecol 1995; 15:295-297. 


\section{Original Research Article}

26. Little RE, Zadorozhnaja TD, Hulchiy OP, Mendel NA, Shkyryak-Nyzhnyk ZA, Chyslovska N, Gladen BC. Placental weight and its ratio to birthweight in a Ukrainian city. Early Hum Dev. 2003 Apr;71(2):11727.

27. Asha, V.K., Meera, P. Study of placental pathology in toxaemias of pregnancy and its foetal importance. India J. Pathol. Microbial, 1981;24: 245:251.

28. Yao AC, Moinian M, Lind J. Distribution of blood between infant and placenta after birth. Lancet. 1969 Oct 25;2(7626):871-3.

29. Leary SD, Godfrey KM, Greenaway LJ, Davill VA, Fall $\mathrm{CH}$. Contribution of the umbilical cord and membranes to untrimmed placental weight. Placenta. 2003 Feb-Mar;24(2-3):276-8.

30. Panti AA, Ekele BA, Nwobodo El, Yakubu A. The relationship between the weight of the placenta and birth weight of the neonate in a Nigerian Hospital. Niger Med J 2012;53:80-4.

31. Heinonen S, Taipale P, Saarikoski S. Weights of placentae from small-for-gestational age infants revisited. Placenta. 2001 May;22(5):399-404.

32. Kloosterman GJ. Intrauterine growth: The significance of prenatal care. Int J Gynaecol Obstet 1970;8:895-912.

33. Baergen RN. The placenta as witness. Clin Perinatol. 2007 Sep;34(3):393-407.

\section{How to cite this article?}

Soni S, Bhardwaj K, Garg S, Mishra S.K. Study of arterial pattern of normal human placenta in reference to its shape, weight and Hyrtl's Anastomosis. Int J Med Res Rev 2017;5(05):455- 461. doi:10.17511/ijmrr. 2017.i05.03. 